\title{
Hydrophobia of gymnosperms: myth or reality? A global analysis
}

\author{
Gregor Kozlowski, ${ }^{1,2 *}$ Markus Stoffel, ${ }^{3,4}$ Sébastien Bétrisey, ${ }^{1}$ Léonard Cardinaux ${ }^{1}$ \\ and Matteo Mota $^{5}$ \\ ${ }^{1}$ Natural History Museum Fribourg, Chemin du Musée 6, CH-1700, Fribourg, Switzerland \\ ${ }^{2}$ Department of Biology and Botanic Garden, University of Fribourg, Chemin du Musée 10, CH-1700, Fribourg, Switzerland \\ ${ }^{3}$ Dendrolab.ch, Institute of Geological Sciences, University of Bern, Baltzerstrasse 1+3, CH-3012, Bern, Switzerland \\ ${ }^{4}$ Institute for Environmental Sciences, Climatic Change and Climate Impacts, University of Geneva, route de Drize 7, CH-1227, Carouge, Switzerland \\ ${ }^{5}$ University of Viticulture and Oenology Changins, Route de Duillier 50, CH-1260 Nyon, Switzerland
}

\begin{abstract}
According to the classical textbooks, the gymnosperms are the only seed plants without aquatic species. Recently, however, a set of virtually complete compilations on gymnosperms has been published, enabling a new evaluation of the putative hydrophobia of gymnosperms. This synthesis aims at portraying the relation of all extant gymnosperm species to aquatic and wetland habitats. We present a database of all 986 extant gymnosperm species with their ecological characteristics including 291 cycads, 80 gnetophytes, one ginkgophyte and 614 conifers. We define four categories reflecting the level of hydrophobia and hydrophily of all species and their possible adaptation to wetlands and/or aquatic habitats. Eighty-two percent (805) of the extant species of gymnosperms are clearly hydrophobic, but 18\% (180) are classified as hydrophilic. The podocarp Retrophyllum minus is the only obligate inhabitant of aquatic habitats. This contribution classifies gymnosperms into four categories in reference to their physiological and morphological adaptation to a moisture gradient. It relativizes the putative hydrophobia of gymnosperms and provides new perspectives for research on gymnosperms. Copyright (c) 2014 John Wiley \& Sons, Ltd.
\end{abstract}

KEY WORDS aquatic plants; conifers; cycads; ginkgoales; gnetales; New Caledonia; Retrophyllum minus

\section{INTRODUCTION}

The conquest of land by vascular plants was a very complex process and plants only gradually adapted their organs and lifestyle to endure the mechanical and physiological rigours of terrestrial life (Sculthorpe, 1967). Originating from waterbound algal life approximately 400 million years ago, they developed new abilities to operate photosynthetically in air while securing water and mineral supply through their root system (Jackson, 1985). In consequence, although their ancestors were aquatic, the most evolved terrestrial plants such as angiosperms and gymnosperms - have become highly intolerant to free water in their environment (Kozlowski, 1997). Adaptations to terrestrial life were so drastic that only a minority of land plants have apparently succeeded in living in sporadically or permanently flooded habitats. In fact, certain properties of water, such as its ability to interfere with free gas exchange, has been demonstrated to injure and kill unadapted terrestrial plants when they are submerged or growing on waterlogged soils (Jackson, 1985; Vartapetian and Jackson, 1997; Jackson and Ram, 2003).

*Correspondence to: Gregor Kozlowski, Natural History Museum Fribourg, Chemin du Musée 6, CH-1700 Fribourg, Switzerland. E-mail: gregor.kozlowski@unifr.ch
Nevertheless, all major groups of terrestrial plants, such as bryophytes, pteridophytes or angiosperms, have rediscovered and populated aquatic environments with hundreds of species - with the apparent exception of gymnosperms. This was at least the categorical conclusion stipulated in the most influential textbooks on aquatic plants published in the course of the 20th century (e.g. Sculthorpe, 1967; Cook, 1990). In particular, gymnosperms have been declared to be the only living vascular plant group without aquatic species in these seminal monographs. The explicitness of this declaration has largely hindered experimental and theoretical studies on aquatic and wetland lifestyle among gymnosperms over the past decades. As a consequence, the putative hydrophobia of this plant group was never really challenged by any exhaustive survey covering all living taxa (Kozlowski, 1997). In addition, the extremely poor knowledge on the ecology of extant gymnosperms (e.g. as far as their habitat preferences are concerned), as well as the uncertainty on the total number of species, rendered global investigations nearly impossible.

The choice to attribute gymnosperms to either hydrophobic or hydrophilic species is all but straightforward given that they belong, without any exception, to either shrubs or trees (Farjon, 2010). In the same line of limitations, the traditional definitions of aquatic (i.e. hydrophytes) and wetland (i.e. helophytes) 
plants are not satisfactory either for woody plants (Sculthorpe, 1967; Cook, 1990; Cronk and Fennessy, 2001). As a matter of fact, the current and rigid definition of hydrophyte as a plant growing permanently in water with submerged photosynthetic parts (Cook, 1990) is too restrictive for trees and shrubs because most of them have been demonstrated to be present in water bodies with varying water levels. In this context, it is less astonishing that mangrove trees have not been considered aquatic plants so far (Cook, 1990), although they are perfectly capable of living almost permanently in water (Tomlinson, 1986; Hogarth, 2007). Interestingly though, similar terminological problems have recently been reported by researchers working on aquatic bryophytes and fungi (Vanderpoorten and Klein, 1999; Shearer et al., 2007). Moreover, because of insufficient ecological knowledge, arbitrary choices have not been unusual in aquatic plant inventories. The decision on whether or not certain species should be considered as inhabitants of aquatic habitats or wetlands is not always straightforward, all the more that a clear demarcation line between open-water aquatic habitats, wetlands and shore vegetation has been missing clearly in the past (Godfrey and Wooten, 1979).

Several virtually complete compilations on gymnosperms have been published recently (e.g. Jones, 2002; Eckenwalder, 2009; Farjon, 2010; Debreczy and Racz, 2011; Earle, 2013). They are delivering an extraordinary wealth of data to explore various aspects of the biologic, biogeographic and evolutionary processes and patterns of this ancient plant group.

Here, we present a first detailed appraisal of all known gymnosperm species worldwide and their relation to aquatic and wetland habitats. A new classification system is used taking account of the level of hydrophobia and hydrophily of gymnosperms. Specifically, the following questions are addressed: (1) What is the level of hydrophobia among all extant gymnosperm species? (2) How many gymnosperm species are facultative inhabitants of waterlogged soils, wetlands, peat bogs, water bodies and/or their shores, and can be described as hydrophilic? (3) Are there any obligate inhabitants of aquatic habitats among gymnosperms? (4) What mechanisms underlie the putative hydrophobia of gymnosperms?

\section{MATERIALS AND METHODS}

To evaluate the level of gymnosperm hydrophobia, we developed a detailed database including all described species with their ecological characteristics. The database takes advantage of open-access online resources (e.g. Catalogue of Life, 2013; Earle, 2013; The Cycad Pages, 2013) and recently published monographs, as well as scholarly pieces on ecological aspects of all taxonomic groups of gymnosperms (e.g. Jones, 2002; Eckenwalder, 2009; Farjon, 2010;
Debreczy and Racz, 2011). For a full list of references used for the creation of the database, see Appendix S1. Only the species level (e.g. no subspecies and/or varieties) has been considered in this paper, resulting in 986 extant gymnosperm species including 291 cycads, 80 gnetophytes, Ginkgo biloba and 614 conifers (Appendix S1).

All species were attributed to one of four categories, reflecting their level of hydrophobia and hydrophily: Category 1 includes obligates that must constantly grow in water. In contrast, category 2 includes facultative species that are physiologically and morphologically adapted to periodic submersion. These gymnosperms possess specialized adaptations to wet environments in the form of root knees, buttressed trunks or the capacity of their seeds to germinate in water. Category 3 includes facultative inhabitants of wetlands and peat bogs. At least one known subspecies, ecotype or population, needs to inhabit one of these habitats to be considered in category 3. Although category 3 species are well supporting waterlogged soils temporarily, they do not show visible morphological adaptation to wet environments. Category 4 contains all gymnosperm species, which never grow in the vicinity of water bodies nor occupy waterlogged soils. Species of category 4 are hydrophobic in the context of this research. In return, species of categories 1-3 are called hydrophilic gymnosperms in the context of this paper (this denomination should not be confound with hydrophilous plants, a term used for aquatic plants with pollination taking place in water or on its surface).

\section{Study taxa}

Gymnosperms represent an ancient seed-plant group that originated about 300 million years ago in the late Carboniferous (Kramer and Green, 1990; Bowe et al., 2000). Recent analyses of molecular data show that all living gymnosperms are monophyletic (Bowe et al., 2000; Chaw et al., 2000; Ran et al., 2010). Gymnosperms are significantly diversified and can be divided into four groups, also called divisions or subclasses: (1) Conifers are by far the largest gymnosperm group with more than 600 extant species and a nearly cosmopolitan distribution (Farjon, 2008, 2010; Eckenwalder, 2009; Debreczy and Racz, 2011). Conifers of the northern hemisphere constitute mainly cone-bearing, long-living trees and shrubs, typical of mountainous and boreal environments (Farjon, 2010). Tropical and southern conifers, by contrast, show a much larger morphological and ecological diversity (Enright and Hill, 1995; Farjon, 2008). (2) Cycads are characterized by palm-like habitus with stout trunks and crowns formed by large, evergreen and pinnate leaves (Jones, 2002). Cycads are divided into three families with almost 300 extant species altogether. They occur across much of the tropical and subtropical regions (The Cycad Pages, 2013). (3) Ginkgophytes were represented by various families and genera during the Mesozoic (252-66 million years before present). 
Only one species has survived, Ginkgo biloba, an endemic to southeast China (Del Tredici et al., 1992; Zhao et al., 2010). (4) Gnetophytes consist of only three extant and - at first sight - very differing genera with around 80 species (Catalogue of Life, 2013; Earle, 2013). The Gnetum has species of woody climbers, rarely trees, in tropical forests. The Ephedra genus is composed of species of shrubs that grow along shores or sandy soil, mostly in the northern hemisphere. The third genus, Welwitschia, is endemic to the desert regions of Angola and Namibia (McCoy et al., 2008; Earle, 2013).

All in all, gymnosperms number about 1000 species, tiny in comparison with Angiosperms, which exceed 300000 . In addition, angiosperms also are the most diverse group among all living terrestrial plants. Together with gymnosperms, they are part of seed-producing plants (Spermatophyta). Although they diverged from gymnosperms already more than 200 million years ago, angiosperms only became more widespread and started to replace conifers from a majority of habitat types around 60-100 million years ago (Bowe et al., 2000; Soltis and Soltis, 2004; Soltis et al., 2005).

\section{RESULTS}

According to the classification used in our global survey, a large majority of extant species (805 gymnosperms, representing 82\%) are clearly hydrophobic (Figure 1). At the same time, however, this means that at least 181 gymnosperms (18\%) can be classified as hydrophilic because they have proven to be flood-resistant or at least well adapted to inhabit wetlands, peat bogs or water bodies (categories 1-3, Appendix S1). Among the conifer families, the Podocarpaceae, Pinaceae and Cupressaceae have the largest absolute numbers of hydrophilic species (Figure 1 and Appendix S2) with 58, 47 and 29 species, respectively. More generally, conifers seem to exhibit a much lower level of hydrophobia (75\%) as compared with gnetophytes (94\%) and cycads (92\%), which represent the most hydrophobic groups among gymnosperms. Ginkgo biloba, the only living ginkgophyte, is never growing in the vicinity of water bodies. The rare hydrophilic gnetophytes comprise mainly species growing along rivers in swampy lowland tropical forests (Figure 1; Earle, 2013). A slightly larger number of hydrophilic species is observed in cycads with 22 species; they grow mainly along rivers and streams or in tropical mangrove swamps (Figure 1; Jones, 2002).

One of the most exceptional species among all living gymnosperms is the podocarp Retrophyllum minus (Figure 2a). To our knowledge, R. minus represents the only obligate inhabitant of aquatic habitats among gymnosperms (Appendices S1 and S2). This dwarfed tree, characterized by

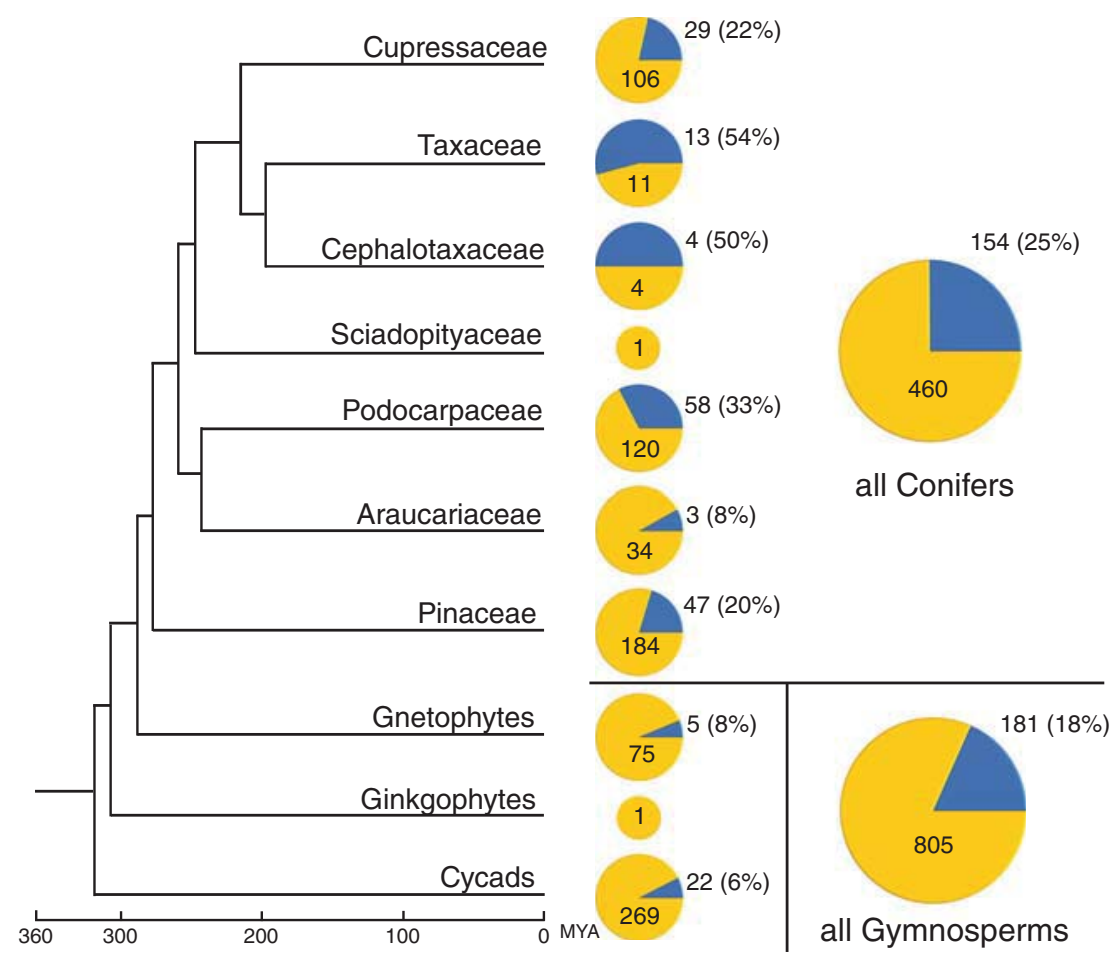

Figure 1. Gymnosperms and their relation to water. All 986 extant taxa included in our survey are divided into four main taxonomic groups (cycads, ginkgophytes, gnetophytes and conifers). Conifers, the most diverse group, are further divided into seven families. The phylogenetic division and time scale is based on Ran et al. (2010). Blue: hydrophilic species (facultative or obligate inhabitants of wetlands, peat bogs, water bodies and/or their shores, well supporting waterlogged soils), regrouping all taxa from the categories $1-3$. Yellow: hydrophobic species (never growing in vicinity of wetlands and water bodies, and not supporting waterlogged soils, category 4). The division and meaning of the gymnosperm categories is explained in the Section on Materials and Methods. 

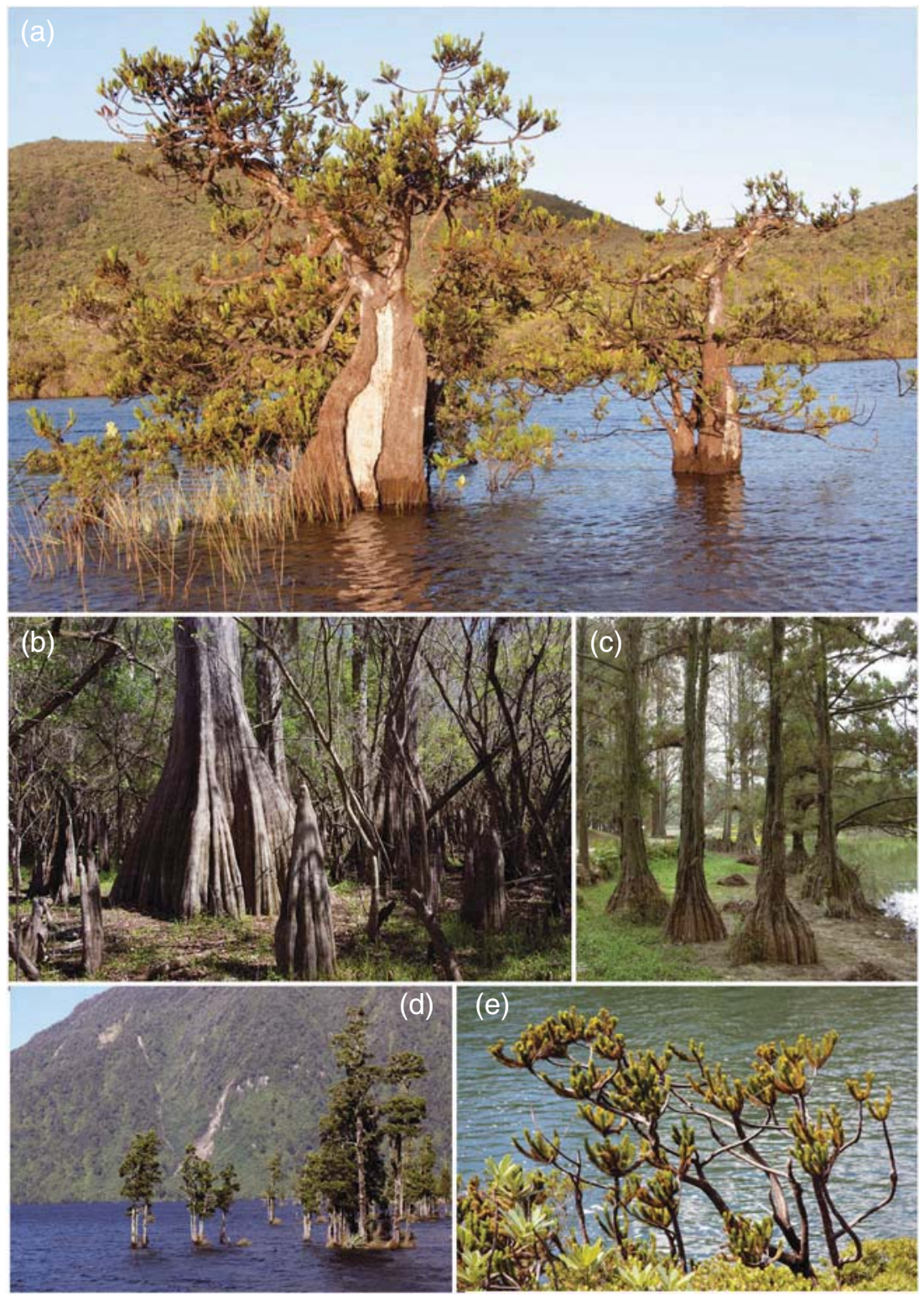

Figure 2. Eccentrics among gymnosperms. (a) Retrophyllum minus, endemic to the pacific island New Caledonia, is the only obligate inhabitant of aquatic habitats among all living gymnosperms (category 1). The species from $b$ to e are facultative inhabitants of water bodies, well supporting waterlogged soils and possessing special adaptations such as buttressed trunks, root knees or the capacity of germination in water (category 2): (b) Taxodium distichum from Florida, USA. (c) Glyptostrobus pensilis from southeastern Asia. (d) Dacrycarpus dacrydioides endemic to New Zealand. (e) Dacrydium guillauminii endemic to New Caledonia. All these species belong to only two conifer families: Podocarpaceae (a, d, e) and Cupressaceae (b, c). Photography credits: Matteo Mota (a, e), Michel Roggo (b), Ouyang Pei (c) and Emanuel Gerber (d). The division and meaning of the gymnosperm categories is explained in the Section on Materials and Methods.

a very thick and spongy bark, is a narrow endemic of New Caledonia, where it grows exclusively in small rivers of the Plaine des Lacs (de Laubenfels, 1972; Farjon, 2008).

In addition, at least five other gymnosperms can grow in water for the major part of the year and are therefore showing extraordinary adaptation strategies for aquatic lifestyle (category 2). Besides the two species of Taxodium (Cupressaceae), a native genus to North and Central America, category 2 also encloses Glyptostrobus pensilis (Cupressaceae) from China, Dacrycarpus dacrydioides (Podocarpaceae) from New
Zealand and Dacrydium guillauminii (Podocarpaceae) from New Caledonia (Figure 2, Appendix S2).

\section{DISCUSSION}

How gymnosperms combat their hydrophobia?

The fact that several extant gymnosperms are indeed highly hydrophilic raises intriguing questions and puts the putative hydrophobia of gymnosperms into question. Above all, this 
discovery opens new research fields and calls for investigations focusing on allometric characteristics, which would have allowed category 1 and 2 gymnosperms to dwell in water. The most visible and widespread phenomenon present in all hydrophilic species is their stem hypertrophy, also known as buttressing (Figure 2). This increase in basal stem diameter is reflective of accelerated cell expansion induced by cell separation and rupture. The process of stem hypertrophy has been shown to be stimulated by ethylene, which in turn causes an increase in porosity of the tree base and thereby enhances aeration (Cronk and Fennessy, 2001). Furthermore, a larger stem base also provides additional support and improved anchorage for these shallow-rooted trees growing on wet substrate. The two Taxodium species and G.pensilis have been described to possess further structural properties in the form of 'root knees' (Figure 2b), which in turn improve their adaptive capacity to wet environments. In addition to providing enhanced structural support and stabilization, root knees presumably also play a key role in gas exchange (Briand, 2001; Earle, 2013).

Moreover, evidence exists that other Cupressaceae (e.g. Metasequoia glyptostroboides) or Taxaceae (e.g. Torreya taxifolia) might present hypertrophy in their stem base (Farjon, 2010; Earle, 2013), which is considered typical for hydrophilic gymnosperms as well. As a result, there is scope and reason for these species to be included in category 2 as well. The unexpected discovery of several new large conifers during the past two decades (Farjon, 2008), among them Wollemia nobilis, a relict Araucariaceae growing in New South Wales (Australia; Earle, 2013), demonstrates that finding new hydrophilic gymnosperms is still possible.

In terms of reproduction strategies, Taxodium spp., R. minus and D. guillauminii seem to have developed specific reproduction strategies (e.g. seed dispersal by water, germination in water) for their life in aquatic conditions (Earle, 2013). The adaptive capacity to flooding and anoxic conditions - articulated in the production of aerenchyma, adventitious roots and/or lenticel hypertrophy - is, in contrast, a widespread phenomenon among gymnosperms and therefore not a specific characteristic of hydrophilic species (Kozlowski, 1997; Cronk and Fennessy, 2001).

\section{Why does a majority of gymnosperms remain ill adapted to aquatic environments?}

On the basis of the aforementioned considerations on allometric adaptations of gymnosperms to water, one should also investigate the evolutionary, anatomical and/or physiological features that would have hampered gymnosperms to be more successful in colonizing aquatic environments. Several possible explanations for the unadaptiveness of gymnosperms to the wet are provided in the following.

In a first attempt to explain the widespread hydrophobia of gymnosperms, one could allude to the apparent evolutionary superiority of angiosperms over gymnosperms (Burger, 1981; Stebbins, 1981), as well as to the associated tremendous and successful spread of angiosperms and related decline of gymnosperms over the last 100 million years (Bond, 1989). Doubtlessly, the superior reproductive strategies and rapid reproduction cycles, mutualism with animal pollinators and dispersers, varied arrays of biochemical defenses and high diversity of growth forms clearly made (and still do so today) angiosperms much better competitors (Bond, 1989; Enright and Hill, 1995; Williams, 2009), even more so in habitats with high frequency of disturbance regimes, and in aquatic habitats in particular.

The exceptional position and isolation of New Caledonia, which separated some 85 and 55 million years ago from Australia and New Zealand, respectively, seems to support such a hypothesis. As a result of New Caledonia's early separation from Gondwana, its sustained isolation ever since and its particular geology (e.g. ultramafic soils), the colonization of the island with angiosperms and their competition with gymnosperms have been much less pronounced than anywhere else on earth (Morat et al., 1994; Jaffré et al., 1998), therefore explaining the extraordinary success, adaptation and unique ecological diversification of New Caledonian gymnosperms

Indeed, our survey indicates that the status of New Caledonia is exceptional. Although very small in area, the island hosts $7 \%$ (or 45 ) of all conifer species, all of them island endemics and some of them with unique characteristics (e.g. the only parasitic gymnosperm species Parasitaxus usta, Podocarpaceae; de Laubenfels, 1972). In addition to $R$. minus and D. guillauminii (categories 1 and 2 respectively), several other New Caledonian conifers seem to grow exclusively in the vicinity of water (category 3), for instance, Podocarpus novae-caledoniae, Dacrycarpus vieillardii (both Podocarpaceae), and to a lesser extent also Callitris sulcata and Neocallitropsis pancheri (both Cupressaceae) (Appendix S1; de Laubenfels, 1972; Steenis, 1981). A majority of these species are severely endangered today as only small numbers of individuals and/or only a handful of populations are remaining (Jaffré et al., 1998; Farjon, 2010).

The superiority of angiosperms cannot, however, be the singular explanation of the scarcity of aquatic gymnosperms. The current body of paleontological evidence does not provide for example any hints to any aquatic form of gymnosperms over the first 200 million years of their dominancy, i.e. long before the powerful expansion of angiosperms.

The hydrophobia of a large majority of gymnosperms might therefore be reflective of their more rigid life form and ancient reproduction strategies (Williams, 2009). All extant aquatic representatives of angiosperms can be characterized as extremely plastic in somatic organization, commonly expressed by noticeable heterophylly and very fast growth. Moreover, the development of herbaceous habit entailed angiosperms to far more effectively explore and colonize 
ephemeral habitats (Bond, 1989; Soltis and Soltis, 2004; Sperry et al., 2006). Gymnosperms, in contrast, remained restricted to woody plants, majorly slow-growing and longliving organisms, and clearly lacking similar morphological plasticity (Burger, 1981; Stebbins, 1981). Forming a specialized group, which has become perfectly adapted to terrestrial life, gymnosperms have coevally remained highly unfitted to very dynamic aquatic habitats with abrupt changes in water level or rapidly flowing water. Their reproduction strategy is also much more rigid than that of angiosperms (Williams, 2009), with mating being almost exclusively dependent on air and wind pollination - the pollination by insects in Welwitschia is the big exception in the picture (Earle, 2013). The large absence of pollination vectors, widespread in angiosperms, might be thus another argument for the inferiority and absence of gymnosperms in wet environments (Williams, 2009).

On a different line of thoughts, the saturation of substrates or soils with water has also been demonstrated to exclude the access of higher plants to oxygen (Vartapetian and Jackson, 1997). The response of higher plants to soil waterlogging has been explored intensively (Parent et al., 2007; Ashraf, 2012), but only rarely, if ever, with the aim of understanding evolutionary differences between angiosperms and gymnosperms. In a majority of plants, tissue hypoxia or anoxia inevitably suppresses energy-generating systems to operate, and thereby disturbs functional relationships between roots and shoots, in addition to suppress carbon assimilation and photosynthesis. Gymnosperms, as other higher plants, are aerobes and depend upon supply of molecular oxygen from their environment to support respiration and other lifesustaining reactions (Vartapetian and Jackson, 1997). At the same time, however, only well-adapted plants can support longer oxygen deprivation in the case of submergence. A majority of gymnosperms, and in particular conifers, have been demonstrated to suffer from low flooding tolerance with decreased root and needle growth, root decay, and with the formation of abnormal wood and bark tissues (Yamamoto et al., 1987; Kozlowski, 1997).

Further elements of explanation for the widespread hydrophobia of gymnosperms and their scarce occurrence in wet environments could be found in their wood and stem anatomy (Ewers, 1985; Sperry, 2003). The evolution and large presence of xylem vessels has been considered one of the key innovations and main drivers for the predominance of angiosperms in higher plants. However, the absence of vessels in some basal flowering plant groups (e.g. Amborellaceae; Feild et al., 2000), and their presence in certain gnetophytes (e.g. Gnetum; Muhammad and Sattler, 1982), calls for a re-examination of this hypothesis. Gymnosperm tracheids are generally also more resistant to solute flow than angiosperm vessels and thus have a less efficient transport system. Hence, maximum growth rates of gymnosperms will be lower on open, sunny sites and well-watered habitats as compared with those of angiosperms (Bond, 1989), because their very narrow tracheids and weakly vascularized evergreen leaves (which are most obvious in conifers) make them much more adapted to water deficiency and coevally less suited to conquest waterlogged soils (Bond, 1989; Sperry et al., 2006). Because transport properties of conifer tracheids are superior to those of angiosperm vessels in water- and nutrient-limited habitats (but not vice-versa!) and under freezing stress (Sperry et al., 2006; Stoffel and Hitz, 2008), the first (and conifers in particular) have largely colonized temperate arid, boreal and mountain ecosystems of the northern hemisphere (Farjon, 2010), whereas the latter conquered habitats where water and nutrient limitations were less important.

\section{CONCLUSIONS}

In contrast to the 300000 species of omnipresent angiosperms, many aspects of gymnosperm evolution, ecology and biogeography are still waiting thorough scientific investigation. The marginality, small size of gymnosperms - with less than 1000 living species - and their assumed inferiority as compared with angiosperms might, however, be a key for better understanding of evolutionary processes in seed plants.

According to estimates, only $1 \%$ of all angiosperms and $2 \%$ of the pteridopyhtes are indeed aquatics (Cook, 1990), and up to one third of all vascular plant species are capable to grow in wetlands or waterlogged soils (Reed, 1988; Tiner, 1991). In this paper, we demonstrate that $18 \%$ of all gymnosperm species are in fact wetland inhabitant and that almost $1 \%$ of them are perfectly adapted to aquatic habitats. Our study therefore proves, for the first time ever, that gymnosperms are not much different from vascular plant groups as far as hydrophobia is concerned. On the basis of our global survey, we also provide substantial evidence for the existence of hydrophilic gymnosperms and thereby put the famed hydrophobia of gymnosperms into perspective.

On the other hand, however, the existence of only one obligate aquatic gymnosperm and five category 2 species gives rise to a large body of new scientific issues and thus calls for new research. As a matter of fact, we still do not know why gymnosperms, although present on earth for more than 300 million years and famed for having been an extremely successful plant group in the past (Ran et al., 2010), developed only a handful of species inseparable from water. This observation is even more surprising as at least one of the potential ancestors of gymnosperms, the fossil genus Cordaites, presumably was a freshwater paralic swamp taxon with stilt roots (Falcon-Lang and Bashforth, 2005; Raymond et al., 2010). The discovery of more fossil aquatic gymnosperm species - although doubted by many scientists (Sculthorpe, 1967) - cannot be completely excluded, not least because modern gymnosperms represent only a small 
taxonomic and ecological fraction of what once was part of a rich Mesozoic flora (Williams, 2009).

Many of the hydrophilic gymnosperms described here are at the brink of extinction. Notably, the only obligate aquatic gymnosperm, $R$. minus, possesses no more than four localized natural populations on New Caledonia, and the poorly studied G. pensilis is probably extinct in the wild in China, and extremely rare in Laos and Vietnam (Debreczy and Racz, 2011; Thomas et al., 2011). Our contribution shall, thus, deliver additional reasons to intensify research and conservation efforts for these unique and endangered conifers.

More research is needed to improve our understanding of what features enabled these scarce and rather eccentric gymnosperms to dwell in water to combat their hydrophobia. In a similar way, future work should look at similarities and differences in morphology, anatomy and physiology of buttressed stems of water dwelling gymnosperms. What were (and still are) the specific adaptation traits that allowed these species to successfully germinate and establish their seedlings in aquatic habitats? And how unique is in fact the only obligate water inhabitant from New Caledonia, R. minus, in comparison with other hydrophilic gymnosperms?

\section{ACKNOWLEDGEMENTS}

We thank E. Gerber and A. Fasel from the Natural History Museum Fribourg (Switzerland) for their generous support to undertake this study. Special thanks are going to $\mathbf{M}$. Roggo, E. Gerber and O. Pei for providing photographs and to Estelle Arbellay for insightful comments.

\section{REFERENCES}

Ashraf MA. 2012. Waterlogging stress in plants: a review. African Journal of Agricultural Research 7: 1976-1981.

Bond WJ. 1989. The tortoise and the hare: ecology of angiosperm dominance and gymnosperm persistence. Biological Journal of the Linnean Society 36: 227-249.

Bowe LM, Coat G, dePamphilis CW. 2000. Phylogeny of seed plants based on all three genomic components: extant gymnosperms are monophyletic and Gnetales' closest relatives are conifers. PNAS 97: 4092-4097.

Briand CH. 2001. Cypress knees: an enduring enigma. Arnoldia 60: 19-25.

Burger WC. 1981. Why are there so many kinds of flowering plants? BioScience 31: 577-581.

Catalogue of Life (CoL). 2013. Available from: http://www. catalogueoflife.org (accessed June 2013)

Chaw S-W, Parkinson CL, Cheng Y, Vincent T, Palmer JD. 2000. Seed plant phylogeny inferred from all three plant genomes: monophyly of extant gymnoseprms and origin of Gnetales from conifers. PNAS 97: 4086-4091.

Cook CDK. 1990. Aquatic Plant Book. SPB Academic Publishing: The Hague.

Cronk JK, Fennessy MS. 2001. Water Plants: Biology and Ecology. Lewis Publishers: Boca Raton.

Debreczy Z, Racz I. 2011. Conifers Around the World. Conifers of the Temperate Zones and Adjacent Regions. DendroPress Ltd.: Budapest.

Del Tredici J, Ling H, Yang G. 1992. The Ginkgos of Tian Mu Shan. Conservation Biology 6: 202-209.
Earle CJ. 2013. The Gymnosperm Databank. Available from http://www. conifers.org (accessed June 2013)

Eckenwalder JE. 2009. Conifers of the World. The Complete Reference. Timber Press: Portland.

Enright NJ, Hill RS. 1995. Ecology of the Southern Conifers. Smithsonian Institution Press: Washington.

Ewers FW. 1985. Xylem structure and water conduction in conifer trees, dicot trees, and lianas. IAWA Bulletin 6: 309-317.

Falcon-Lang HJ, Bashforth AR. 2005. Morphology, anatomy, and upland ecology of large cordaitalean trees from the Middle Pennsylvanian of Newfoundland. Review of Palaeobotany and Palynology 135: 223-243.

Farjon A. 2008. A Natural History of Conifers. Timber Press: Portland.

Farjon A. 2010. A Handbook of the World's Conifers. Brill: Leiden Boston.

Feild TS, Zwieniecki MA, Brodribb TJ, Jaffré T. 2000. Structure and function of tracheary elements in Amborella trichopoda. International Journal of Plant Sciences 161: 705-712.

Godfrey RK, Wooten JW. 1979. Aquatic and Wetland Plants of Southern United States. The University of Georgia Press: Athens.

Hogarth P. 2007. The Biology of Mangroves and Seagrasses. Oxford University Press: Oxford.

Jackson MB. 1985. Ethylene and responses of plants to soil waterlogging and submergence. Annual Review of Plant Physiology 36: $145-174$.

Jackson MB, Ram PC. 2003. Physiological and molecular basis of susceptibility and tolerance of rice plants to complete submergence. Annals of Botany 91: 227-241.

Jaffré T, Bouchet P, Veillon J-M. 1998. Threatened plants of New Caledonia: is the system of protected areas adequate? Biodiversity and Conservation 7: 109-135.

Jones DL. 2002. Cycads of the World. Smithsonian Institution Press: Washington.

Kozlowski TT. 1997. Responses of woody plants to flooding and salinity. Tree Physiology Monographs 1: 1-29.

Kramer KU, Green PS. 1990. The families and genera of vascular plants. Volume I. Pteridophytes and Gymnosperms. Springer: Berlin.

de Laubenfels DJ. 1972. Flore de la Nouvelle Calédonie et dependences, Vol. 4. Muséum National d'Histoire Naturelle: Paris.

McCoy SR, Kuehl JV, Boore JL, Raubeson LA. 2008. The complete plastid genome sequence of Welwitschia mirabilis: an unusually compact plastome with accelerated divergence. BMC Evolutionary Biology 8: 130.

Morat P, Jaffré T, Veillon J-M. 1994. Richesse et affinités floristiques de la Nouvelle Calédonie: conséquences directe de son histoire géologique. Mémoires de la Société de Biogéographie 4: 111-123.

Muhammad AF, Sattler R. 1982. Vessel structure of Gnetum and the origin of angiosperms. American Journal of Botany 69: 1004-1021.

Parent C, Capelli N, Berger A, Crèvecoeur M, Dat JF. 2007. An overview of plant responses to soil waterlogging. Plant Stress 2: 20-27.

Ran J-H, Gao H, Wang X-Q. 2010. Fast evolution of the retroprocessed mitochondrial rps3 gene in Conifer II and further evidence for the phylogeny of gymnosperms. Molecular Phylogenetics and Evolution 54: $136-149$.

Raymond A, Lambert L, Costanza S, Slone EJ, Cutlip PC. 2010. Cordaiteans in paleotropical wetlands: an ecological re-evaluation. International Journal of Coastal Geology 83: 248-265.

Reed PB Jr. 1988. National list of plant species that occur in wetlands: national summary. Biological Report 88: 1-244.

Sculthorpe CD. 1967. The biology of Aquatic Vascular Plants. Edward Arnolds Publishers Ltd.: London.

Shearer CA, Descals E, Kohlmeyer B, Kohlmeyer J, Marvanova L, Padgett D, Porter D, Raja HA, Schmit JP, Thorton HA, Voglymayr H. 2007. Fungal biodiversity in aquatic habitats. Biodiverity and Conservation 16: 49-67.

Soltis PS, Soltis DE. 2004. The origin and diversification of angiosperms. American Journal of Botany 91: 1614-1626.

Soltis DE, Soltis PS, Endress PK (eds). 2005. Phylogeny and Evolution of the Angiosperms. Sinauer: Sunderland.

Sperry JS. 2003. Evolution of water transport and xylem structure. International Journal of Plant Sciences 164: 115-127. 
Sperry JS, Hacke UG, Pittermann J. 2006. Size and function in conifer tracheids and angiosperm vessels. American Journal of Botany 93: 1490-1500.

Stebbins GL. 1981. Why are there so many species of flowering plants? BioScience 31: 573-577.

Steenis CGGJ van. 1981. Rheophytes of the World. An Account of the Flood-Resistant Flowering Plants and Ferns and the Theory of Autonomous Evolution. Sijthoff and Noorghoff: Alphen aan den Rijn.

Stoffel M, Hitz OM. 2008. Snow avalanche and rockfall impacts leave different anatomical signatures in tree rings of Larix decidua. Tree Physiology 28: 1713-1720.

The Cycad Pages. 2013. Available from: http://plantnet.rbgsyd.nsw.gov. au/PlantNet/cycad/ (accessed June 2013)

Thomas P, Yang Y, Farjon A, Nguyen D, Liao W. 2011. Glyptostrobus pensilis. IUCN Red List of Threatened Species. Version 2012.2. Available from: www.iucnredlist.org (accessed June 2013)

Tiner RW. 1991. The concept of a hydrophyte for wetland identification. BioScience 41: 236-247.

Tomlinson PB. 1986. The Botany of Mangroves. Cambridge University Press: New York.
Vanderpoorten A, Klein J-P. 1999. A comparative study of the hydrophyte flora from the Alpine Rhine to Middle Rhine. Application to the conservation of the Upper Rhine aquatic ecosystems. Biological Conservation 87: 163-172.

Vartapetian BB, Jackson MB. 1997. Plant adaptations to anaerobic stress. Annals of Botany 79: 3-20.

Williams CG. 2009. Conifer Reproductive Biology. Springer: New York. Yamamoto F, Kozlowski TT, Wolter KE. 1987. Effect of flooding on growth, stem anatomy, and ethylene production of Pinus halepensis seedlings. Canadian Journal of Forest Research 17: 69-79.

Zhao Y, Paule J, Fu C, Koch MA. 2010. Out of China: distribution history of Ginkgo biloba L. Taxon 59: 495-504.

\section{SUPPORTING INFORMATION}

Additional supporting information may be found in the online version of this article 